\title{
The Relationship Between Microenterprises and Socioeconomic Development Among Youth Group in Addis Ababa, Ethiopia
}

\author{
Markos Kidane', Dugassa Mulugeta ${ }^{2}$, Addis Adera $^{3,}$, , Yonas Yimam ${ }^{3}$, Tigabu Molla ${ }^{4}$ \\ ${ }^{1}$ Department of Economics, Faculty of Business and Economics, Unity University, Addis Ababa, Ethiopia \\ ${ }^{2}$ Departments of Economics, Faculty of Business and Economics, Addis Ababa University, Addis Ababa, Ethiopia \\ ${ }^{3}$ Department of Nursing, Faculty of Health Sciences, Woldia University, North Wollo, Amhara Region, Ethiopia \\ ${ }^{4}$ Department of Economics, Faculty of Business and Economics, Woldia University, North Wollo, Amhara Region, Ethiopia
}

\section{Email address:}

markos.kidane@yahoo.com (M. Kidane), addisaderagebru@gmail.com (D. Mulugeta), yonasyimam@gmail.com (Y. Yimam), jenetoforum@yahoo.com (T. Molla), addisaderagebru@gmail.com (A. Adera)

\section{To cite this article:}

Markos Kidane, Dugassa Mulugeta, Addis Adera, Yonas Yimam, Tigabu Molla. The Relationship Between Microenterprises and Socioeconomic Development Among Youth Group in Addis Ababa, Ethiopia. Journal of World Economic Research.

Vol. 4, No. 3, 2015, pp. 61-70. doi: 10.11648/j.jwer.20150403.12

\begin{abstract}
Back Ground The unemployment rate of youth group is currently $31.46 \%$ in Addis Ababa. Moreover, it is believed that, as the major source of social problem to youth group is "lowest economic capacity". Objective: The main objective of this study was to assess the relationship between microenterprises and socioeconomic development among youth group in Addis Ababa, Ethiopia. Method: A survey based study was used to collect data on the relationship between microenterprises and socioeconomic development among youth group in Addis Ababa, Micro and Small Enterprise Program started before 7 years (2004) it has to be changed in to 2003G.C. This program targeted different parties of the society (MSE 2010). The total of 120 micro enterprises which operated by youth groups. The sampling method was involved in ten sub-cities of Addis Ababa. The major micro and small enterprise activity identification was based on the available information from MSE packages and selected randomly. Data analysis was made by using descriptive statistics. Results: The findings of this study have vital implications to poverty reduction, employment creation, women empowerment of microenterprises, and the use of consultancy services by microenterprises targeting youth group for the growth of their enterprises. The major constraints of the sector, specifically, for youth target microenterprises, such as place; credit access; and misunderstanding, disagreement and mistrust among group members has to be addressed. This could be achieved by coordination of the different stakeholders of the sector such as Addis Ababa City Municipality, Addis Ababa MSE Agency, Addis Ababa Youth Association, Microfinance Institutions, and NGOs. Moreover, different supports for youth group microenterprises have to be continuing and it has to be strengthening, furthermore, such supports have to be more of growth oriented. Since, the results of the study shows that majority of youth targeting micro enterprises are not using consultancy services, the stake holders of the sector has to provide favorable conditions. Conclusion: Most of the respondents believed that employment in microenterprises could reduce poverty, and leveled as high in terms of its extent of importance to poverty reduction. From the available psychosocial constraints afraid of failure and criticism, faulty socialization, and low dignity of labor and inadequate motivation are the most serious problems that young entrepreneurs are facing.
\end{abstract}

Keywords: Microenterprises, Socioeconomic Development, Youth Group, Associated Factors

\section{Back Ground}

The challenge of development is to improve the quality of life. Especially in the world's poor countries, a better quality of life calls for higher incomes - but involves much more. It encompasses as ends in themselves better education, higher standard of health and nutrition, less poverty, a cleaner environment, more equality of opportunity, greater individual freedom and a richer cultural life. This is why modern development economists (Raj. Flex., 2006; Mengistu et al., 
2013), has to be conceived of as a multi - dimensional process involving major changes in social structure, people's attitudes, and national institution, in addition to the acceleration of economic growth, alleviation of poverty and reduction of income inequality (Raj. Flex., 2006; Mengistu et al.,2013;Asian Development Bank.,1997). Micro enterprise development projects can serve for four major objectives: (1) poverty reduction; (2) empowerment of women; (3) employment generation; and, (4) enterprise development as an end in itself (Federal Democratic Republic of Ethiopia., 2010; UN Economic Commission for Africa., 2008; Moyi., 2013). MSEs development has been considered as a key to economic development throughout the so-called third world for several decades. With unemployment rate of ranging from 25 to 45 percent in most developing countries, "selfemployment" and "micro enterprise development "is seen by many donor agencies as the only way to reach the "poorest of the poor" (Abebe and Belay., 2005). Small and micro enterprises seen to be the sources of income, employment, skills, goods and services etc. for people in developing countries. Even though, no conclusive studies has been undertaken on micro enterprises, both the urban and rural Ethiopian have been the beneficiaries of the economic units (Micro and Small Enterprise., 2011; Ministry of Finance and Economic Development., 2010; Achieng., 2013). Accordingly, Addis Ababa city Administration micro and small enterprise development program had started seven years ago, with the objective of alleviating poverty and reducing unemployment. The development program would run by an independent organization with the name of Micro and Small Enterprise Development Agency; it has ten branch offices at sub city level and116 sub branch offices at woreda level. The program have been given due attention for seven growth oriented sectors, including textile and garment, metal and wood work, construction, food processing, municipal activity, coble stone and urban agriculture. The program has been implemented by having different target groups. These are TVET graduates from different fields of studies, poor and unemployed women, street beggars (due to premises problem), MSE operators under high risk (e.g. Metal workers, operators, on walkways, open air) business operators, disabled people with different skills and all enterprise operating within the selected subsectors' (Urban Employment Unemployment Survey., 2009). Thus, improving the economic capacity of youth group can solve the multidimensional problems of youth (i.e. both men and women) in their social activity. This in turns, to reduce problems in related to HIV/AIDS dissemination, child mortality rate, and unemployment; contributions to poverty alleviation, women empowerment, and economic growth, which are in general, could bring economic development. In order to solve such problems, different strategies could be available. Hence, it is believed that micro-enterprises could enhance economic capacity of people mainly in terms of poverty alleviation, women empowerment, and reducing unemployment (MOFED, 2011; Desai, 2009; Hamde, 2012; Ethiopia Central Statistical Agency., 2010). Other than the fast population growth, the inability of the economy to generate sufficient employment opportunities and low productivity, low skills of the working poor, including those operating in smallholder agriculture, and the informal economy contributes to the high incidence of poverty and ever-increasing unemployment problems. Underemployment and unemployment constitute serious challenges especially in urban areas and among the youth. It is important to note that the pressure on the labor market comes from the supply of labor which in turn induced by the growth rate of population. Due to the growing labor supply and limited employment opportunities, there is lot of interests in building the capacity of the informal economy that employed a sufficient portion of the labor force. On one hand, cooperatives have been identified as key elements of the PASDEP. In improving livelihoods of the people, more than $85 \%$ of population depends and works in the agricultural sector. Some of the challenges faced by the cooperatives include strong competition in the new liberal market environment, shortage of capital, inaccessibility to credit, low management skill of board members, etc. The challenges are even more critical when it comes to the participation of women and youth in cooperatives (Altekar. 2007; Parisotto, 2007; Vanklinken, 2008; MOFED, 2010; CSA's., 2010). In this respect, the policy formulation process requires an assessment of the current- status, shortcomings and prospects of micro enterprises. The main objective of this study was to assess the relationship between microenterprises and socioeconomic development among youth group in Addis Ababa, Ethiopia.

This study has been organized in to four chapters. The first chapter deals with the problem and its approach such as objective of the study, research methodology, scope of the study, significance of the study, definition of used terms, and limitation of the study. The second chapter is concerned with presenting the review of related literature, which is vital for the further look of the subject matter and for the accomplishment of the study. Moreover, this part comprised of both theoretical and empirical related literature reviews. The third chapter treats the data collection, the analysis of the data collected and its interpretation. This part is undertaking by using both primary and secondary data that were collected by the researcher of this study. The fourth chapter is an end to this study, which consists of summary of findings, conclusion and recommendation. Lastly, necessary documents attached at the end of this study such as references. An enterprise is group of people with a common goal, having resources (money, manpower, materials, machines, technologies etc.) to achieve that goal.

\section{Operational Definitions}

The term "micro-enterprise" connotes different entities and sectors depending on the country. Generally speaking, in developing countries comprise the vast majority of the small business sector - a result of the relative lack of formal sector jobs available for the poor. These micro entrepreneurs operate micro enterprises not by choice, but out of necessity, where as in developed countries, micro enterprises comprise the smallest end (by size) of the small business sector.

Micro enterprise development: - refers to the package of 
services, policies, programs, and institutions intended to develop micro enterprises.

Micro finance: - refers to the package of micro financial services including lending and saving.

Micro finance institutions:-refers to institutions that provide micro finance services. These may include nongovernmental institutions, credit cooperatives, credit unions and banks.

Non-financial services-refers to the collection of programs and services that deliver inputs other than finance. They are sometimes referred to as business development services. Examples are technical skills, training, business training, marketing information and assistance, design and other forms of product development, technology transfer, assistance in the procurement of raw materials, the development of organizations of micro entrepreneurs, and so on.

Social intermediation: - describes training and other support that may be provide to prospective poor borrowers to help them acquire skills and values which they need to initiate micro enterprises. Social intermediation services include training in credit norms and procedures, saving discipline, and assistance in organizing in to groups. Because it is the other coin of credit delivery, it is not generally regarded as a non-financial service.

\section{Methods and Methodology}

\subsection{Method of Data Collection}

In order to gather the necessary data and information, the researcher undertaken the following methods: Interview: The study undertake interview to the concerned governmental, non-governmental, social, financial organizations in order to gather the necessary data. The selection of these organization held on the basis of information available in Addis Ababa micro and small enterprise agency in which, participating in terms of micro and small enterprises promotion in different aspects. Interview method was undertaken by the use of organized interview guide, which attached at the end of this study under the annex part. This method enabled the researcher of this study, to have a further look on the heterogeneous micro-enterprises, and to their overall understanding through implementing it in the study sample focus group. This in turn resulted to obtain sufficient inputs to data analysis. Questionnaires: This study have undertaken by accompanying structured and unstructured questionnaires, which believed as essential for investigating the necessary information, and in turn enabled this researcher to achieve its general and specific objectives. Direct Observation: This study undertook direct observation for the sake of further understanding to micro enterprises undertaken by youth groups in Addis Ababa. The available data on micro enterprises specifically to youth group is limited, scattered and not organized. This study collected pieces of information from various sources, in order to analyze the status, shortcomings, and prospects of micro enterprise target youth group in Addis Ababa.

\subsection{Method of Analysis}

This study used descriptive analysis. The data analysis were made by using descriptive to describe the characteristics of the sample and to make judgments about the characteristics of whole population i.e. Addis Ababa. The analysis were based on the available essential documents, published or unpublished (i.e. on basis of primary and secondary data). Additionally, the study was used statistical measures, flow diagrams, flow charts, tables, graphs, and pie charts for effective data analysis and presentation purpose. . Moreover, Microsoft Excel 2007 and Microsoft Word 2007 were used for effective analysis purpose.

Statistical measures such as measures of arithmetic mean, and count were used as per the need during data analysis and presentation. In addition, other techniques such as frequency and percentile were implemented in this study.

\subsection{The Study Area and Period}

Addis Ababa is the highest city in terms of size, microenterprise concentration, and urban population in Ethiopia. The unemployment rate is expected $31.46 \%$ according to CSA Statistical Report on the 2010 Urban Employment Unemployment Survey. In Addis Ababa, Micro and Small Enterprise Program started before 7 years (1996). This program targeted different parties of the society. Despite, this study covers micro enterprises targeting youth group in Addis Ababa.

\subsection{Description of the Study Design}

This study was used both qualitative and quantitative approaches. The quantitative approach used survey method in order to form a database from which to infer relationships of population. This study practiced a survey method by using sampling techniques such as stratified, random and, purposive sampling techniques.

\subsection{Research Design}

Generally, under economic, social, and business researches: importance is given to historical, case study, and survey research methods. Each of the above methods has their own advantages and disadvantages. However, the researcher has to have a priori knowledge to their advantages and disadvantages of each methods stated before. However, understanding of the research area subject matter is critical in selection of a research method. The researcher of this study tried to understand the various aspects of micro-enterprises through gathering different information to the various aspects of micro enterprises and youth groups specifically in Addis Ababa. Thus, by accompanying the above stated factors and other advantages of the specified method together with the presence of the available information to micro enterprises targeting youth group in the case of Addis Ababa, the researcher of this study intended to select a survey method. However, the selection of this method dictated by taking in to consideration factors such as techniques of investigation. 
Hence, survey method is the technique of gathering data from population by applying personal contact, and interview when adequate information about a certain problem is not available in records, files and other sources. To this end, the availability of data to micro enterprises targeting youth group in Addis Ababa is very limited. Thus, the limitation of organized data, specifically to the aspects of this study, the researcher of this study intended to use a survey method. Despite, a survey research is an organized attempt to analyze, interpret, and report the present status of social institution group area, thus, the researcher of this study believed it as the better method to undertake this study effectively and to look beyond. The researcher used interview, questionnaire and direct observation techniques for the sake of data collection.

\subsection{Sampling Method}

Firstly, the sampling method was involved in ten sub-cities of Addis Ababa. The sampling distribution across sub cities of Addis Ababa dictated by, the available financial and time resources.

Secondly, the major micro and small enterprise activity identification were based on the available information from MSE packages prepared by Addis Ababa MSE Agency and selected randomly.

Then, the sample of 120 micro enterprises were selected and distributed across all sub cities randomly.

\subsection{Types of Data}

This study used both primary and secondary data, which is vital for the accomplishment of this study as it should be. Secondary data included small- scale industry survey of years (2002-2008 G.C) undertaken by Ethiopian Statistics Agency and data on microenterprises gathered by Addis Ababa Micro and Small Enterprises Agency. It also included reports of Addis Ababa youth association and other stakeholders which are involving in small and micro enterprise development.

Primary data collection was in terms of both quantitative and qualitative forms. This researcher believes that the inclusion of primary data enabled this study to accompany the necessary information in realities of Addis Ababa, specifically, micro enterprises targeting youth group, which in turn results to look this study, as it should be.

\subsection{Sampling Procedure and Data Collection}

This study used a survey method in order to gather the primary data from youth group microenterprises in Addis Ababa. In order to gather the necessary data, the researcher also used interview, observation, and both organized and non-organized questionnaires.

The interview method were under taken by interviewing workers of Addis Ababa City Administration Micro and Small Enterprises Agency, Addis Ababa Youth Association, CSA, Addis Ababa Credit and Saving institutions, and some micro enterprise operators who belongs to youth category. Observation method were done by observing Cobble Stone projects, Micro and small enterprises promotional exhibition in Arada and Gullele sub-cities, and other micro enterprise activities such as urban agriculture, food processing and construction activities specifically undertaking by youths. This study also used questionnaire method, which has been performed in two stages. First, the questionnaires were prepared in English language for the sake of fulfilling academic medium of instruction. Then, the questioners interpreted in to Amharic language for the sake of simplification (easiness) for respondents. Since, the respondents academic background differs, the researcher believed that being the questionnaires interpreted in to Amharic language, respondent of youth micro enterprise operators can respond easily which in turn enables to gather the necessary data and information. The Amharic questioner-form attached at the annex part of this study see annex number 3 . Despite, the questioners were prepared by using organized and non- organized questionnaire methods. After the questionnaire interpreted and prepared by Amharic language, distributed to ten selected sub cities randomly. Then, while the questionnaires were distributed, it was done by finding "Kebele" offices in each sub cities and thus through asking information "Kebele" workers to the location of youth target micro enterprises. After the location of youth group micro enterprises identified, the questionnaires were provided to youth micro enterprise operators-owners, then, the questionnaires were collected after they were filled by youth micro enterprise operators (respondents of questionnaires), immediately, the questionnaires were checked for errors and were returned back for respondents to correct errors. After the abovementioned steps, the questionnaires became ready to data encoding stage. After the results of the questionnaires were collected and became ready for data encoding stage, the collected questionnaires were coded from one to one hundred twenty. This task was made for the easiness of correcting data encoding errors. After that, the coded questionnaires also coded, in a manner to be easy for SPSS data encoding purpose (i.e. each questions and choices). Then, the collected data encoded to SPSS version 13.0. The data encoding activity were made in two steps. First, the coded questions and their respective choices were encoded under variable view category of SPSS version 13.0 software, furthermore, name of variable, data type, label, and values of each question were encoded. Second, the values of each coded question and their respective choice were encoded to the data view category of SPSS version 13.0 software. Next, the encoded data checked for data encoding errors. Afterwards, the encoded data became cleaned and ready for analysis purpose.

\subsubsection{Data Quality Control}

Pretest was conducted in 5\% of the study population in Addis Ababa selected for study to assess the reliability of data collection instruments. The questionnaire was prepared in English and translated to Amharic for interview. The completeness of the questionnaire was checked during and after collection. 


\subsubsection{Ethical Considerations}

Formal letter written from Unity University, Faculty of Business and Economics and permission from Addis Ababa Sub cities administrative office were obtained to conduct the study. The study participants were informed about the purpose of the study and informed verbal consent was obtained from each participants before data collection. Finally confidentiality was assured and the data was kept by avoiding personal identifiers. The result of the study was disseminated to Department of Economics, office of Unity University, Faculty of Business and Economics. In addition to this the finding of the study provided and disseminated to local Department of Economics, the nearby Business and Economics institutions and to Zonal Economic department to update information and make use of it for intervention.

\section{Results}

\subsection{The Relatedness of the Respondents' Educational Background to their Current Job}

The relatedness of the respondents' educational background to their current job is shown in table 1 below. From the total respondents $39.2 \%$ of them have a related educational background to their current job. To this respect, the relatedness of their educational background to their current job could help them for the growth and expansion of their enterprises development. Hence, the relatedness of their educational background to their current job, have a positive effect on the production of their quality outputs, entrepreneur activities (i.e. innovation and, invention of new products), customers satisfaction, are expected to high growth and which in turns to be become small enterprises.

Table 1. Profile of youth respondents to the relatedness of their educational background and current job.

\begin{tabular}{llllll}
\hline \multicolumn{2}{l}{ Related educational background } & Frequency & Percent & Valid percent \\
\hline \multirow{3}{*}{ Valid } & Yes & 47 & 39.2 & 39.2 & Cumulative percent \\
& No & 73 & 60.8 & 60.8 \\
& Total & 120 & 100 & 100 \\
\hline
\end{tabular}

For those youth microenterprises, operators whose educational background not related to their current job will not be more profitable as compared to those who have related educational background. Moreover, their growth rates also less even if they provided different supports such as expertise technical, business development skills, book keeping, entrepreneurial, and other trainings. Most likely, majority of them could be categorizing in to the livelihood programs. However, they have also a probability of growth and expansion by using consultancy services, improving their academic status, and through changing their academic profession to their business activity. They can also improve their problems through employing professionals. Even if they categorized in to livelihood programs by improving their awareness to growth factors it is possible it is possible to change these enterprises to growth-oriented microenterprises.

\subsection{Distributions of Respondents in Each Sub-Cities of Addis Ababa City Administration}

This study survey included seven sub cities in its sample. These sub cities are Yeka, Arada, Nifas Silk- Lafto, Addis Ketema, Gulelle, Bole, Akaki- Kaliti, Kirkos, Kolfe-Keranio, and Lideta Sub cities. During data collection as it was been stated in the methodology part of this study, the researcher used random sampling method, which were guided by the available financial resources. Moreover, this study also used purposive sampling method in order to find youth microenterprises operators in Addis Ababa. The percentage distributions of respondents in each sub city included in this survey sample presented diagrammatically by using pie chart in figure 1 as follows:-

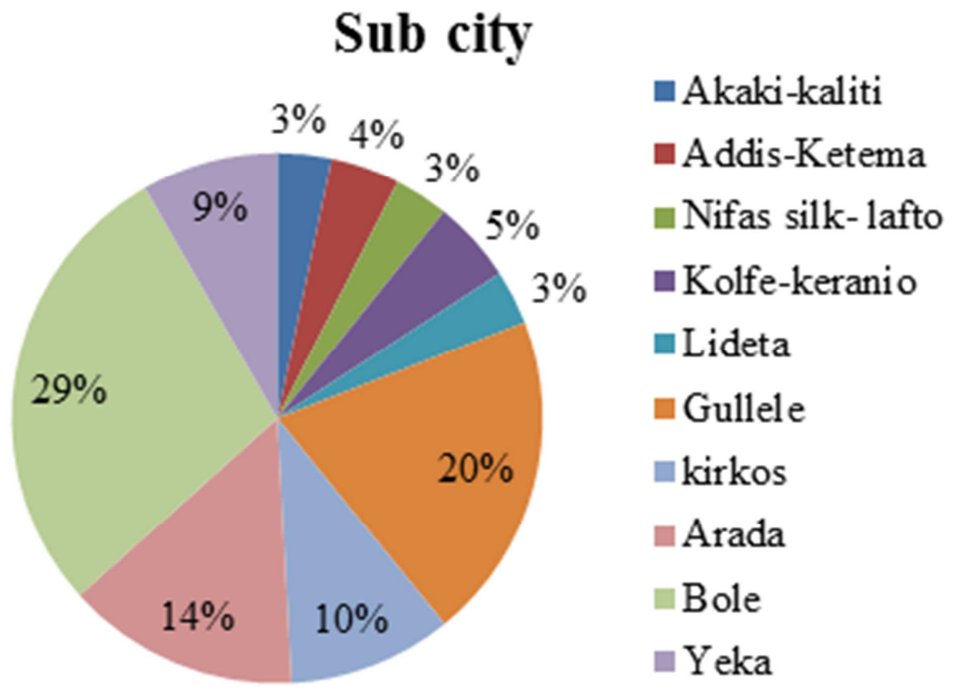

Fig. 1. Percentage distributions of respondents in each sub-cities of Addis Ababa City Administration. 


\subsection{Establishments of Youth Targeting Microenterprises}

According to this study survey result, $17.5 \%$ of micro enterprises formed before $1997,47.5 \%$ of them were from

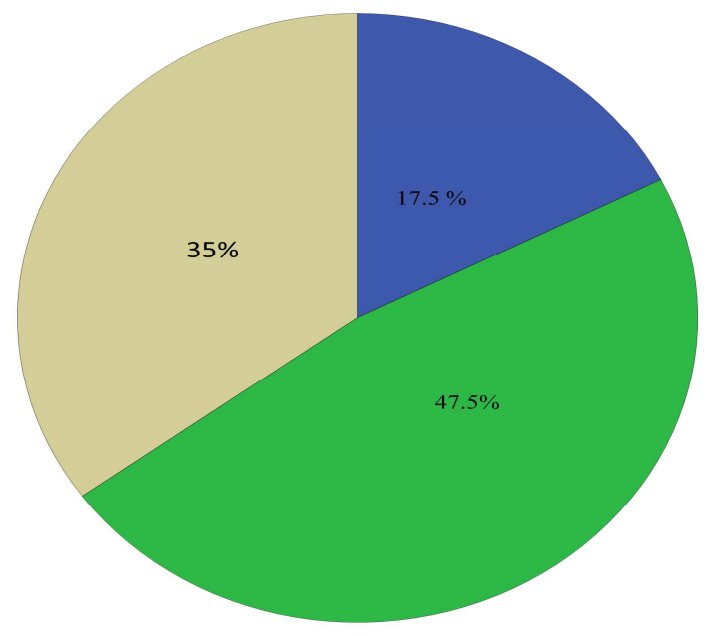

1997-2000, and the remaining $35 \%$ of them formed after 2000. This result presented diagrammatically by using pie chart figure 2 as follows:

- Before 1997

- From 1997-2000

After 2000

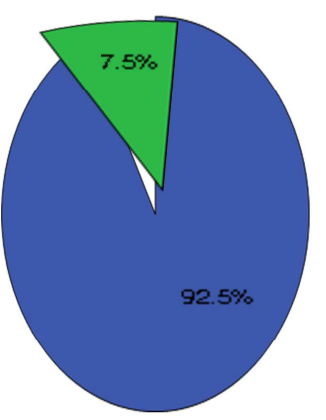

Fig. 2. Establishments of youth targeting microenterprises.

\subsection{Microenterprises and Vision Settings}

In terms of setting a vision to their enterprises, youth targeting micro enterprises that are included in this study survey sample responded that, from the total number of respondents $91.7 \%$ of them were set their vision, $7.5 \%$ of them were not set their vision to their microenterprises and it is presented in the following figure number 3 as follows:
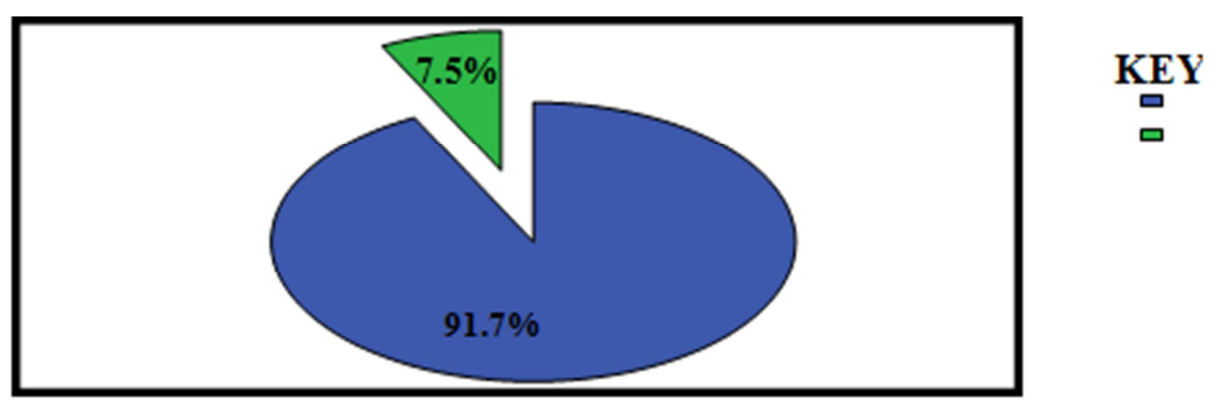

Fig. 3. Setting /not setting vision to youth targeting Microenterprises micro enterprises (in years).

On the other hand, from the total respondents of youth targeting micro enterprises that were set their vision $30.8 \%$ of them were set their vision before they started in such activities, the remaining $29.2 \%$ and $35 \%$ of them were set their vision at the start up and during operation of microenterprises respectively. This result presented in figure 4 as follows:

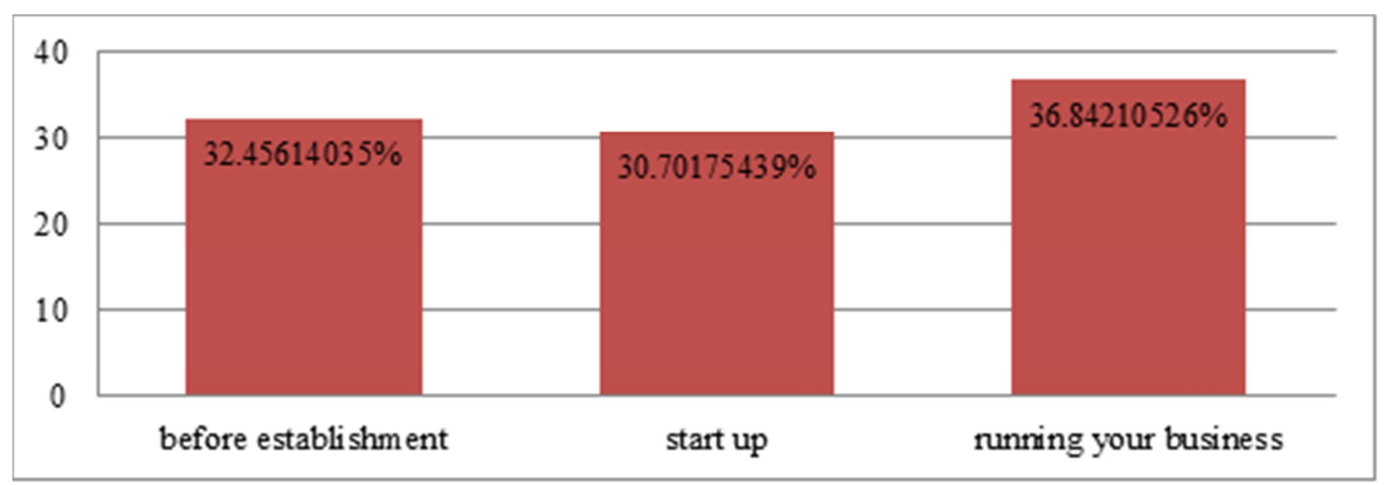

Fig. 4. Youth targeting microenterprises vision establishment. 


\subsection{Organizational Supports to Youth Target Microenterprises}

In terms of the different supports provided by governmental and nongovernmental organizations to youth targeting micro enterprise operators in Addis Ababa, the results of this study sample survey shows that, $66.7 \%$ of the respondents were responded that youth targeting microenterprises were benefited from the different supports that they were obtained from governmental and nongovernmental organizations. The remaining $25.8 \%$ of them believed that they were not beneficiaries. However, from the total number of respondents who responded as they were benefited from the different supports that they were obtained, the contribution of government, nongovernment, and both government and nongovernment organizations presented in table 2 as below

Table 2. Distributions of governmental and nongovernmental organizations in terms of their supports for youth target microenterprises in Addis Ababa.

\begin{tabular}{lllll}
\hline \multicolumn{2}{l}{ Distributions of organizations support to youth targeting micro enterprises } & & \\
\hline Serial no. & Types of organizations & Frequency & Percent & Cumulative Percent \\
1 & Governmental & 51 & 62.9 & 62.9 \\
2 & Non-governmental & 7 & 8.6 & 71.6 \\
3 & Both & 23 & 28.4 & 100 \\
& Total & 81 & 100 & \\
\hline
\end{tabular}

As the above table shows, majority of youth target microenterprises obtained different supports from governmental organizations and which accounts to $62.96 \%$.In terms of the kinds of supports which provided by governmental and nongovernmental organizations, the results of this study sample survey presented in figure 5 as follows:

\subsubsection{Kinds of Supports Provided by Governmental and Non-Governmental Organizations to Youth Target Microenterprises}

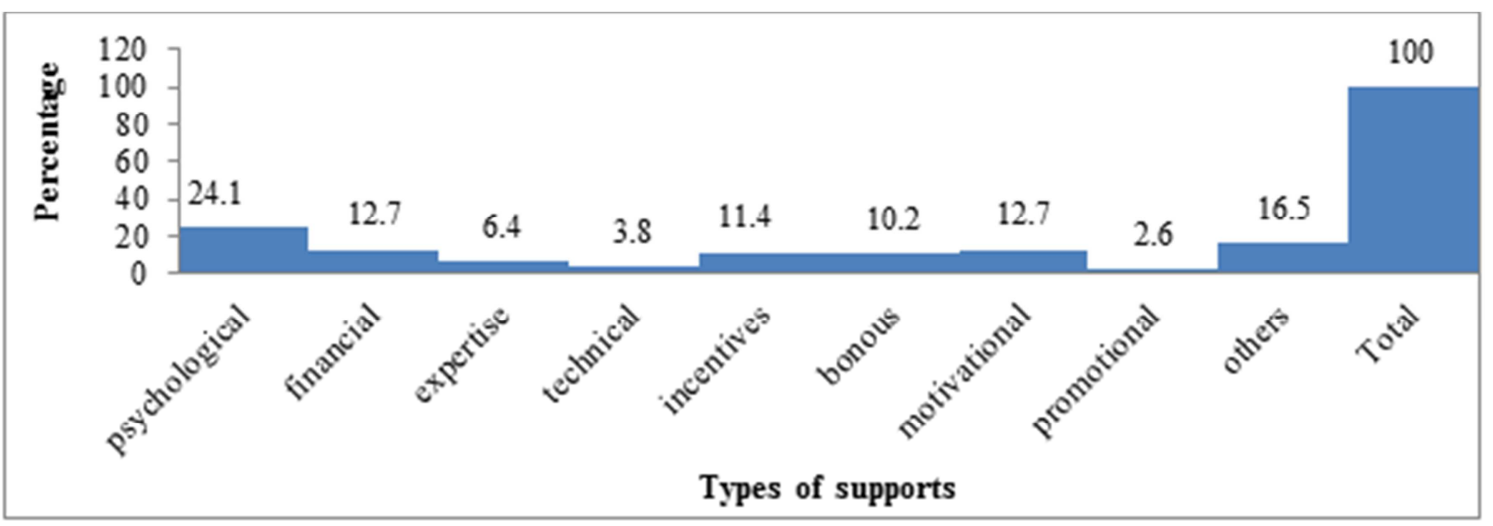

Fig. 5. Kinds of supports provided by governmental and non-governmental organizations to youth target microenterprises.

From the total respondents $24 \%$ of microenterprises were obtained psychological supports, $12.65 \%$ of them obtained financial supports, $6.3 \%$ of them obtained expertise, $3.7 \%$ of them obtained thecnical, $11.3 \%$ of them obtained incentives, $10 \%$ of them bonus, $12.6 \%$ of them motivational, $2.53 \%$ of them promotional and $16.5 \%$ of them obtained other supports from governmental and nongovernmental organizations. Others include a combination of two or more supports which was mentioned above and promises of different supports in the future.

\subsubsection{The Essentiality of Governmental And/Non- Governmental Organizations Support to Youth Target Microenterprises}

Even if $34.2 \%$ of the total respondents responded that were not obtain any support from governmental and nongovernmental organizations, they leveled its essentiality as very important, important, and moderate.

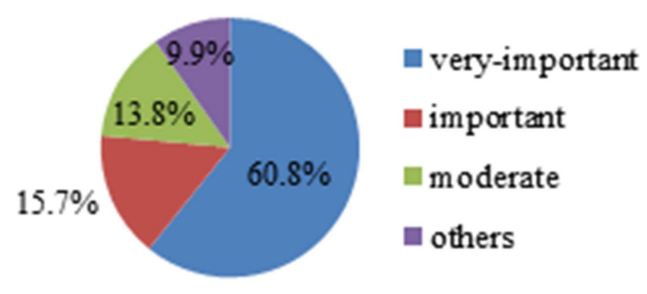

Fig. 6. Responses to the essentiality of governmental and/non-governmental organizations support to youth target microenterprises. 


\section{Discussions}

In terms of the different supports provided by governmental and nongovernmental organizations to youth targeting micro enterprise operators in Addis Ababa, the results of this survey study shows that, majority of youth targeting microenterprises benefited from the different supports which obtained from governmental and nongovernmental organizations. Out of these, majority of youth group microenterprises were get different supports from governmental organizations. However, from the total number of respondents who responded as "youth target microenterprises were not obtained any support from the different supports provided by governmental and nongovernmental organizations", majority of them leveled its essentiality as very important for the growth of their enterprises. Furthermore, majority of youth target microenterprises had provided financial and non-financial supports from Addis Ababa MSE Agency. Even if supports i.e. financial and non - financial supports has provided to those micro enterprises, they are also demanding different supports from Addis Ababa MSE Agency in the future. To this respect, majority of the respondents are demanding growth oriented supports that could enable them to grow their enterprises in to small and medium enterprises. The results of this survey findings shows that from the different supports provided by youth targeting microenterprises, psychological and financial supports are the major supports to female operators. Moreover, majority of microenterprises operating by youths were undertaking quality control and quality standards. However, from the total number of microenterprises which undertaking quality control and quality standard activities, most of these microenterprises are undertaking controls over production. On the other hand, microenterprises, which are not undertaking quality control and quality standards, were due to different reasons, these are absence of testing facilities, attitude of microenterprises operators as it is not necessary for their enterprise, lack of technical skills to undertake, and high cost from higher to lower reasons hierarchically. The basis of young entrepreneurs location setting for their microenterprises is due to different factors, however, the results of this study shows that majority of them were set their location because an authorized body provided the current location to their microenterprises. According to this survey study findings majority of youth group microenterprises are not using consultancy services, which accounts to $68.3 \%$, and their major reason were lack of awareness. However, from the total number of microenterprises, which were using consultancy services, majority of them identified as very important for the growth and expansion of their enterprises. Additionally, majority of young entrepreneurs' basis of product selection relies on consumers need and market demand, production, government policy and educational background, idea generation through group discussion, and the location of micro enterprises sequentially.

\section{Weakness and Strength}

\subsection{Strength}

The strength of the article are the survey based study and its interpretation

\subsection{Weakness}

The weaknesses of the article are its structure and some formal but important sides.

\section{Conclusion}

The majority of young entrepreneurs' basis of product selection relies on consumers need and market demand, production, government policy and educational background, idea generation through group discussion, and the location of micro enterprises sequentially. Thus, youth entrepreneurs should select their products based on market research since; it enables them to have market demand and in turn to be profitable. However, product selection through group discussion and idea generation has to be encouraged and such cultures have to be adopt by other microenterprise operators, hence, such an experience results entrepreneurial culture development. Furthermore, there has to be a strategy to change their product selection philosophy to marketing and if possible to societal marketing. Furthermore, different supports (financial and non- financial) that were provide for youth group microenterprises have to be continuing and it has to be strengthening. Furthermore, such supports have to be more of growth oriented such as growth-oriented trainings and education like effective retained earning implementations, quality control and standardizations. Hence, majority of such enterprises were obtain their source of initial capital from microfinance institutions, they are playing a great role in terms of poverty reduction, employment and growth of micro enterprises especially for youth targeting micro enterprises. Therefore, it has to be strengthening. Furthermore, such institutions have to create favorable environments for youth targeting microenterprises such as fast credit access, systematic and easy collateral, and terms of payment. Based on Asian tiger's country experience, knowledge/human capital, the prospective plan of GTP, new educational policy and also from different perspectives, interdisciplinary courses of entrepreneurship, development psychology, critical thinking and systems theory has to be provided for them. To this respect, together with the new 70-30 educational policy the achievement of GTP is surmountable. Whenever low income of youths starts rising, both the demand side and supply side of youths changes. In the demand side, when youth's low income start increasing then the purchasing power also increases. The increase in the purchasing power of youths results to an increase in the inducement to invest and in turn results to an increase for capital. The increase for capital also results to an increase in 
productivity, which results to an increase in income in which the circle of demand side completed. Then, an increase in income also lets to an increase of every element in the demand side, which continues as per the income of microenterprises increases. Similarly, in the supply side, an increase in the level income of youths through raising income through micro enterprises results to an increase in youth's capacity to save and which in turn results to an increase in youth's capital. An increase in youth's capital also results to an increase to the productivity of youths and which results to an increase in income and which in turn results to the complete circle of the supply side. Hence, microenterprises require relatively small amount of initial capital and this can be maximize through increasing the working labor forces in such enterprises. As a result, poor youths (i.e. the have-nots) could change their enterprises to a growth oriented by forming groups. Hence, they can use their absolute advantages i.e. idle labor force. To this end, youths could facilitate the economic growth and development behind poverty alleviation.

\section{Author's Contributions}

MKA have made substantial contributions to beginning and design, collection of data, analysis and interpretation of data and in drafting the manuscripts and correcting the comment given by the advisors.

DM involved in revising the research paper and the manuscript critically with important intellectual context; also participated in the approval of the final version to be published in its design and coordination. He participated in the approval and funding process, participated in the design of the study participated in its design and coordination.

AAG had greater contribution in reviewing the manuscript English and topography and helped to draft the manuscript.

YYA and TM had greater contribution in reviewing the manuscript English and topography and helped to draft the manuscript.

\section{Acknowledgements}

We are thankful to all our department technical staffs for their excellent technical support. We are grateful to all the participants for their cooperation and all my best friends and my families for financial support during this successful research. We would like to acknowledge gratefully for Science PG Journal due to their cooperation and funding for this publication.

\section{References}

[1] Abebe, G., Belay, G. (2005) Micro Business Development in Ethiopia. In Wolday Amha et. al. (Eds) (2005.). Small-Scale Enterprise Development in Ethiopia, Proceedings of the Sixth Annual Conference on the Ethiopian Economy. Ethiopian Economic Association (EEA); Addis Ababa University, Department of Economics. Addis Ababa.
[2] Altekar, R V. (2007) Enterprise Wide Resource Planning: Theory and Practice. 4th Printed. Prentice Hall of India Private Limited. New Delhi, India.

[3] Achieng, M (2013). Assessing the Readiness by SMEs and Financial Institutions in The Establishment of an Integrated ICT Infrastructure for Financial Transactions in Kenya, International Journal of Intelligent Information Systems. 2(1) : 40-45. doi: 10.11648/j.ijiis.20130202.13

[4] Asian Development Bank (ADB) (1997 G.C). Micro Enterprise Development: Not By Credit Alone. Asian Development Bank. (n.p).

[5] CSA (Central Statistical Agency) (2010). Manual, Central Statistical Agency, February2001, Ethiopia[eth], Amharic [amh], "Doc\Technical\Enumerators_manual-2010.pdf"

[6] CSA (Central Statistical Agency) (2009).Urban Employment Unemployment Survey 2009 (2002 E.C) - Supervisor's Manual, Central Statistical Agency, February 2009, Ethiopia [eth], Amharic [amh], "Doc\Technical Supervisor_Manual2010.pdf"

[7] CSA (Central Statistical Agency) (2010 G.C).Statistical Report on 2010 Urban Employment Unemployment Survey. Printed in CSA. Addis Ababa, Ethiopia.

[8] CSA (Central Statistical Agency) (2010 G.C).Statistical Report on 2010 Urban Employment Unemployment Survey: Addis Ababa City Administration. Printed in CSA. Addis Ababa, Ethiopia.

[9] CSA (Central Statistical Agency) (2010). Ethiopia Central Statistical Agency, Ministry of Finance and Economic Development(2011) .Urban Employment Unemployment Survey 2010 (2003 E.C)

[10] Desai, V. (2009). The Dynamics of Entrepreneurial Development and Management. Preventing and Mitigating AIDS in Sub-Saharan Africa: Research and Data Priorities for the Social and Behavioral Sciences 2nd Edition, New Delhi: Himalaya Pub. House,

[11] ECA (Economic commission for Africa) (2008). Assessing Progress towards the Millennium Development Goals in Africa - 2008; the UN Economic Commission for Africa, African Union Commission, and African Development Bank, 2008.

[12] FDRE (Federal Democratic Republic of Ethiopia) (2010).Education sector Development program IV (ESDP) from 2010/2011-2014/2015. Program Action Plan .PP1-113, Addis Ababa, Ethiopia.

[13] Hamde, M. (2012). Enterprise wide Resource Altekar, Rahul. V. Prentice- Hall of India planning: theory and of fact: new ash Russell penguin books India for 2007335.

[14] http://www.fao.org/giews/countrybrief/country.jsp?code=ETH for the FAO's Crop Estimates report. CSA's 2010/11 crop estimate data is provided in its October 2011 publication -Agriculture in Figures: Key Findings of the 2008/09 - 2010/11 Agricultural Sample Surveys.

[15] IMF (International Monetary Fund) (2010). Data for government expenditure based on MOFED budget data. Credit to government and credit to public sector figures from the IMF Staff Report of November 2010 (www.imf.org), with FY 2010/11 representing estimates. 
[16] Mengistu K., Mengistu U., Nigussie D., Endrias G., Mohammadamin H., Temesgen K., \& Yemisrach G.(eds.), (2013). Proceedings of the National Conference on 'Loan and Saving: the Role in Ethiopian Socioeconomic Development', 15-16 February 2013, Haramaya, Ethiopia.

[17] MOE (Ministry of Education) (2008): Current Status of Girls Education in Ethiopia. Paper presented at the National Women's Meeting Organized by the Federal Ministry of Women's Affairs on Gender and Educational Equity.

[18] MOFED (Ministry of Finance and Economic Development) (2010). The First Five Years (1998-2002 E.C.) Development Plan Implementation and The next Five Years (2003 to 2007 E.C.) Growth and Transformation Plan Preparation: Inception Report for Panel Discussion to the Federal Government Conference. (n. p).Addis Ababa, Ethiopia.

[19] MOFED (Ministry of Finance and Economic Development) (2010/2011). (for GDP data); IMF REO Oct 2011 and Nov 2010 Staff Report (for monetary, fiscal, investment, BOP data) CSA (for inflation data); National Bank of Ethiopia. Access Capital estimates for most 2010/11 data points and for all 2011/12 projections.

[20] MSE (Micro and Small Enterprise) (2011). Addis Ababa City Administration, Micro and Small Enterprises Agency: Inception Report on Micro and Small Enterprises Development in Addis Ababa. (n.p).Addis Ababa, Ethiopia.
[21] Moyi, ED(2013). Credit and Employment Growth among Small Enterprises in Kenya, International Journal of Business and Economics Research. 2(3): 69-76. doi: 10.11648/j.ijber.20130203.14

[22] Negash, E., Amentie, C. (2013). An Investigation of higher education student's Entrepreneurial intention in Ethiopian Universities: Technology and Business fields in focus Organized by College of Business and Economics, Jimma University. Proceedings of the Fourth Annual Research Conference of Jimma University.95-105.ISBN 978-99944855-0-5

[23] Parisotto, A. (2007). "Local employment generation - LGU practices in the Philippines." Local economic development for employment generation, peace and security: Approaches, tools, and good practices in the Philippines. Report of an ILO-SRO Manila Technical Workshop. Manila: International Labour Office.

[24] Raj, Felix et.al. (2006). Contemporary Development Economics: From Adam Smith to Amartya Sen. New Central Book Agency Pvt. Ltd. Chintamoni Das Lane, India.

[25] Van Klinken, G. (2008). Blood, timber, and the state in West Kalimantan, Indonesia. Asia Pacific Viewpoint. 49(1) pp 3547 